\title{
Intellectual Game Application for Students' Knowledge Control
}

\author{
Romanova Marina Victorovna \\ Power Engineering and Automated Systems Institute \\ NMSTU \\ Magnitogorsk, Russia \\ romanova.mv@mail.ru
}

\author{
Romanov Evgeny Petrovich \\ History, Philology and Foreign Languages Institute \\ NMSTU \\ Magnitogorsk, Russia \\ Romanov.e@gmail.com
}

\author{
Varfolomeeva Tatiana Nikolaevna \\ Power Engineering and Automated Systems Institute \\ NMSTU \\ Magnitogorsk, Russia \\ tani64@mail.ru
}

\begin{abstract}
Innovative approach to teaching assumes the use of interactive methods and techniques not only for organizing the training process but also for controlling students' knowledge. Thus, the problem of finding and describing interactive, the most efficient students' knowledge control methods arises. The article focuses on various interactive students' knowledge control methods; analyses their opportunities on the basis of teachers' and the students' activity analysis and the mechanism of their interaction; actualization of students' motivational sphere and their need for self-rating and estimation. Intellectual game is reasoned as one of efficient students' knowledge control methods. The technique of using intellectual games for students' knowledge control that is based on the contextual principle, the principle of interlocution and reflexivity is described. The set of rules and the procedures containing a complex of methods which provide the logic of phases for carrying out intellectual games is stated. The elaborated methodology of students' knowledge control is offered for "interactive" students' knowledge control which is conceptually based on creative potential of students, development of their cognitive abilities, and formation of their abilities for auto analysis and self-rating and estimation. The value of the offered methodology consists in its application that gives the chance to carry out both training, and assessment of knowledge at different stages of the current, intermediate and total control on the unified basis while studying different disciplines.
\end{abstract}

Keywords: intellectual game; knowledge control; interactive methods; high school

\section{INTRODUCTION}

In modern conditions the market needs welltrained competent high-professional specialists who

\author{
Lomakina Yekaterina Alexandrovna \\ History, Philology and Foreign Languages Institute \\ NMSTU \\ Magnitogorsk, Russia \\ leakaty@mail.ru
}

Chernova Elena Vladimirovna

Power Engineering and Automated Systems Institute NMSTU

Magnitogorsk, Russia

hellenachernova@mail.ru

Ruban Konstantin Alexeyevich

Power Engineering and Automated Systems Institute NMSTU

Magnitogorsk, Russia ruban-k@mail.ru

are not only professional competent but possess skills of individual and collective professional activity, the abilities to adapt for the changing conditions of the professional environment and the fast decision-making ability. Higher school scientists and teachers underline a number of the directions that are perspective in higher school training technique development. One of these new ways is methods of interaction of teachers and students that provide efficient pedagogical activity goals ". (Khasiya, 2011, p.120-122)

Pedagogical innovations at the modern Russian higher school are connected both with improvement of traditional models of training and with introduction of new students-oriented models that are focused on students abilities to create their own experience independently.

It should be noted that according to necessary curricula changes the number of classroom activities hours, including the main disciplines, is reduced that causes the necessity of reorganization of the teaching scheme of the material and considerable part of it should be auto-studied by students.

The emphasis of the big importance of students' independent in the course of professional training, new time frames and the different system of students' quality of knowledge estimation put forward a task of searching for new pedagogical decisions that are alternative to the traditional ones.

One of possible decisions is the use of interactive methods not only for educational process organizing but also for controlling students' knowledge. 


\section{GAme TeChNOLOGIES IN EDUCATION}

Interactive technologies are such training and personality developing technologies which are built on "aim-oriented and aim-achieving specially organized group and intergroup activities, "feedback" between all its participants for achievement of mutual understanding and correction of the educational and developing process, individual style of communication, the reflexive analysis or debriefing"( Panfilova, 2009).

There is a set of different types of interactive methods and techniques, but the most widespread and often applied ones are creative tasks, discussion, and game, analysis of concrete situations (case method), project making, round tables, brainstorming, and presentations.

Their analysis of these types of interactive methods and techniques according to such parameters as teachers' and students' activities and their interaction, actualization of students' motivational sphere and their need for a selfassessment at various stages of knowledge control showed that intellectual games are the most efficient knowledge control method.

First of all, we will define the basic concepts of the studied area. «A game is a type of unproductive activity which motive does not consist in its results but in the process" (Soviet Encyclopedic Dictionary, 1988). A.M. Novikov considers that "Like the process of game aborning that takes place in imitation, the process of acquiring knowledge, skills by people is based on a game; humans' social and ideal demands display and realize in a game" (Novikov, 2006).

S. A. Shmakov defines the following features the majority of games (Shmakov, 2004)

- free developing activity that is undertaken in accordance with person's desire, just for fun and getting pleasure from the activity process but not just from the result ("procedural pleasure");

- creative, generally improvisational, active nature of this activity ("creativity field");

- emotional spirits uplifting of the activity, rivalry, competitiveness, competition ("emotional stress");

- presence of the direct or indirect rules that reflect the content of the game, logical and temporary sequence of its development.

Each game is a form of gamble activity and nowadays there is no common classification of games, as "... under the certain circumstances it is possible to invent a game in which nobody has ever played" (Wingenschteil, 1994).

The game technologies concept includes a rather extensive group of pedagogical process organization techniques in the form of different pedagogical games. Unlike general games, a pedagogical game is "a kind of activity which is clearly characterized by a studying goal and the corresponding pedagogical result and an educational and informative orientation" (Shmakov, 2004).

According to the features of the pedagogical process the following groups of games (Shmakov, 2004)are defined:

a) Teaching, training, controlling and summarizing;

b) Informative, educational, cognitive;

c) Reproductive, productive, creative;

d) Communicative, diagnostic, professional orientation, psych technical.

According to the goals the games are divided into 4 main groups (Shmakov, 2004):

1) Didactic: broadening one's outlook, cognitive activity; forming the certain skills that are necessary in practical activities; educational skills developing; labor skills developing.

2) Bringing up: strong will and self-sufficiency forming; certain approaches, positions, moral and esthetic values, worldview forming ; team spirit, cooperative work, collectivism, sociability, communicativeness.

3) Developing: development of attention, memory, speech skills, thinking, abilities to compare and find similes, find analogies, imagination, creative abilities, empathy, reflection, ability to find optimum solutions; development of educational motivation activity.

4) Socializing: familiarizing with norms and values of the society; adaptation to environment conditions; stress control, self-controlling; communication teaching; psychotherapy.

The modern higher educational institution pay great attention to activation and an intensification of educational process that is why game technologies are of great demand:

- they may be used as independent technologies for concept, subject development and even for a subject section development;

- they may be used as elements (sometimes very essential ones) in more complicated technologies

- they may be used as a technology of a lesson or its' part (introduction, explanation, repeating, exercise, control);

- they may be used as technology of extra class activities

\section{INTELLECTUAL GAME AS INTERACTIVE}

Method of Students' KNOWLEdGE CONTROL

Intellectual games "combine game and educational activity features - they develop theoretical thinking, demanding concepts formulation, fulfilling of the main cogitative 
operations (classification, analysis, synthesis, etc.)" (Mandel, 2009).

According to B. Mandel the activity emphases search and decision-making but not the achievement of result on and that becomes an efficient process of continuous students' development during the solution of objectives and problems.

Nowadays the variety of intellectual games is quite great but their essence is unified: "while solving the tasks there is an act of development and creativity, something new exists or creates in them, special qualities of mind, such as observation, ability to compare and analyze, combine, find interactions, regularities, etc. are demanded- this complex in total makes creative and mental abilities of a person, his personal leading socially and professionally significant qualities" (Mandel, 2009).

Intellectual game learns to make fast, difficult, extraordinary decisions and it allows us to understand more efficiently the stated tasks, it forms professional competences and develops reaction speed. The distinctive feature of a game result is information synthesis, generalization of acquired and new knowledge and abilities.

The players have to be able to understand the problem and be able find the solution and analyze the offered ideas and to choose the most efficient way of the problem solution in a limited period of time. "Unpredictability makes an intellectual game an absolutely specific form of cognitive creative activity" (Mandel, 2009).

A game allows a student to develop his intelligence, to mature and with overcoming various difficulties "a game as a social cultural phenomenon is one of the most powerful tools of influence forming and improving not only intellectual development but also communicative skills, social, psychological, personal and professional qualities of a person" (Mandel, 2009).

The competitive component of an intellectual game allows not only to solve a problem of students' knowledge control of at a higher level but also to carry out the teaching function. As researches showed (Filin, 2008) an intellectual game promotes:

- to stimulation students in achieving of educational result;

-to development of team working skills of interaction in the competition conditions; to creation simple scheme of points charge for each module element.

An intellectual game is an individual and personal or command tasks solution that demands productive thinking in the conditions of competition and limited time. As the basic principles of intellectual game that are used for controlling students' knowledge are: context, dialogue, reflexivity.

\section{Context principle.}

An intellectual game must be aim-oriented, accurate rules and subordination for achieving the planned in advance by the teacher game results. During game the aim appears in the form of a game task: to solve a crossword puzzle, to answer quiz questions, to offer your own answer to the problem which forms a certain context (social, professional).A special situation when students should find an answer is created but ready-made ways, means and sources of information for solving the problem don't exist. It assumes an independent way of finding of the solution. The game task consists of an algorithm of an independent information search that is based on transformation, transferring of acquired students' knowledge and abilities.

\section{Dialogue principle.}

Game models often assume small groups work (teams), use of a method of "brainstorming" that demands collective thought creative skills development and also communicative and dialogue skills, business communication and debatable activity skills. During the game generation of ideas, identification and comparison of the points of view, positions, selection of arguments and their presentation go not only in inter team format but also at the inter group level. Thus, the skills of team work of adherents and elements of corporate culture are developed. It is important from the intellectual abilities development point of view and also it is important because of the opportunity to form the balanced critical thinking and the related ability to make the considered, weighed decisions.

\section{Reflexivity principle.}

Competitiveness of games promotes to developing students orientation to positive result. It increases students' self-assessment and satisfaction level with the results of the corresponding subject matter. The reflection helps the student to see himself and his activity from outside, to draw conclusions and, for example, to correct the behavior, activity or to draw up the plan of studying of this or that question. Thus, the final reflexive phase plays an important role, both in the course of game, and in the course of self-development and self-education of the student. This principle is realized at the corresponding stage of game.

\section{PRAXEOLOGICAL ASPECT OF AN INTELLECTUAL GAME OF APPLICATION AS AN INTERACTIVE METHOD OF STUDENTS' ASSESSMENT KNOWLEDGE}

All types of intellectual games ("What? Where? When?", "Your game", "Brain ring", "EruditeQuartette", "Spoonerism", " Without wings», ", "Charades", "Auction""", etc.) which range is rather wide and constantly extends from the pedagogical point of view have much in common as intellectual games are the activity that synthesizes a number of 
pedagogical functions such as developing, communicative, diagnostic, competitive and competitive creative, etc.

In the context of our research we analyzed the possibilities of intellectual games use at various stages of control taking into account such educational methodical requirements as:

1) Supplying the competition as the incentive of quantitative and qualitative increase of knowledge structure;

2) The ability to work in a team;

3) Structuring knowledge;

4) The need of full and accurate knowledge of the basic principles and definitions;

5) The need of detection of strengths of future expert in the course of training;

6) The variety of knowledge control forms that are concluded in unified system;

7) A mark assessment for each element of the monitoring system;

8) Possibility of realization of the majority knowledge control forms in an electronic (electronic and network) format and the detailed analysis of $f$ carrying out. (Filin, 2008)

The analysis of the intellectual games showed that following games have the greatest opportunities: "What? Where? When?", "Your game", "Brain ring", "Erudite-Quartets" and crossword puzzles.

The advantages of students' knowledge control intellectual game application are: a wide localization; team spirit; logical formation communications while searching the answer; possibility of using of special knowledge from different spheres, fundamental definitions and laws and possibility of any procedural modification under concrete requirements.

The disadvantages of students' knowledge control intellectual game application are: impossibility of using highly specialized knowledge while preparing the questions so it makes it difficult to apply the activity for special disciplines, difficulty in differentiation of an individual and command contribution to the decision and necessity of special technical means use.

Application of students' knowledge control intellectual game is linked with some serious difficulties. Elaboration of test lessons in the form of intellectual games presumes deviation from the established principles of control teaching or from official rules of game. What? Where? When?", "Your game", "Brain Ring" and crossword puzzles give a unique opportunity to test students' knowledge in any subject. In total such game elements at control with tasks, tests, laboratory works give extremely full picture of students' knowledge and abilities on disciplines.

These three intellectual games were realized within our research. The importance of their use as the main element of game part of a lesson was empirically confirmed during examination of students of "Business Informatics" department in the following disciplines "Information Security", "Econometrics" and "Electronic Business". As the experiment showed the knowledge assessment at the stage of the current control it is better to carry out in the form of intellectual games such as "Crossword Puzzle" and "Your game", at the stage of the intermediate control - "What? Where? When?" and at the stage of the final control - Brain ring".

As well as in any activity, a game has a preparatory phase, a technological phase (actually carrying out a game), a final (reflexive) phase (Novikov, 2006).

1. A preparatory phase includes material and participants of game preparation process. Elaboration of the essential part of an intellectual game for testing lesson consists of the following stages:

a. Splitting the teaching material into didactic units.

b. Splitting the didactic units into subjects of the theoretical and practical profile.

c. Filling of each subject with the questions and tasks according to traditional hierarchical mark structure.

At this phase the method of analysis, brainstorming and presentation is used. Process of training of players for the organizing and carrying out the game, can be both long and difficult or completely absent when the decision on the game is taken spontaneously or the process of carrying out the game doesn't demand preparation.

2. The technological phase is represented by carrying out the game. This phase depends on a type of the intellectual game. The methods of the phase are discussion, brainstorming, problem tasks, etc.

3. The final a phase is reflection. The player estimates himself and his results (the reflection of the first sort). The player is estimated by the collective: his results, interaction, and behavior in the game, personal features (the reflection of the second sort).

During experiment in the test-trainees groups such features were noted:

1. Higher quantitative and qualitative knowledge level;

2. Ability during the limited interval of time to use the gained knowledge for solving practical (problem, heuristic) tasks;

3. Team interaction skills

\section{V.CONCLUSION}

Thus, as a result of our research is the elaborated methodology of intellectual game application for students' knowledge control, the analysis of its advantages and disadvantages and the 
suggestion of using the "interactive" students' knowledge control that in its conceptual basis is orientated on the creative potential of students, development of their cognitive interests, formation of abilities of introspection and a self-assessment.

\section{References}

[1.] Wingenschteil, L.(1994) Philosophical works, Moscow

[2.] Mandel, B.R. (2009) Intellectual Game: a Sociocultural Phenomenon in the Movement (on the Questions of History and Definition of Essence).Modern Problems of Science and Education, 2, 62-68.

[3.] Novikov, A.M. (2006) Methodology of Game Activity, Moscow, 8

[4.] Panfilova, A.P. (2009). Innovative Pedagogical Technologies. ActiveTraining. Moscow

[5.] Romanova, M.V. (2009) Essence and Content of Game Training with New Information Technologies Application. Southern Ural pedagogical magazine, 1, $46-49$.

[6.] Romanova, M.V., InashviliS.Ya., Turkova E.S (2015)Application of Interactive Methods for Pupils' Examination. World of Science and Innovations. 1 (1). Vol. 6. 65-68

[7.] Soviet Encyclopedic Dictionary. (1988) Moscow

[8.] Filin, I.V. \&Sadovoi A.V. (2008) Elaboration Methodology of Conducting Game Control Lesson in Special Disciplines in Higher Education Institution.Bulletin of the Kremenchug State Polytechnic University, 3 (50), Part 1,43-47

[9.] Filin, I.V. \&Sadovoi A.V. (2008) Application of Intellectual Game Elements for Conducting Test-Lessons at High School. Journal of the National Technical University. "Electric Technics, Electronics and Electric Drive, 30, 600-601.

[10.] Khasiya, T.V. (2011) Pedagogical Innovative Technologies in High School. Actual questions of Modern pedagogy, 120-122.

[11.] Chernova, E.V. \&Dokolin A.S. (2015) Application of Interactive Learning Methods for Preventing Cyber extreme Activities among Young People. Informative and Communicative Space and a Person, Prague, Vědeeckovydavatelské centrum «Sociosféra-CZ».167-172

[12.] Chernova, E.V. (2015) Innovative Educational Technologies in Teaching Bases of Information Security.Electro Technical Systems and Complexes, 1 (26).52-55.

[13.] Shmakov, S.A. (2004) Games of Pupils - a Culture Phenomenon. Moscow

[14.] Moursund, Dave (2007). Introduction to Using Games in Education: A Guide for Teachers and Parents. Retrieved from http://pages.uoregon.edu/moursund/Books/Games/Games. pdf

[15.] Five Reasons to Use Games in the Classroom (2013) Retrieved from http://www.educationworld.com/a_curr/reasons-to-playgames-in-the-classroom. shtml

[16.] McClarty, Katie Larsen Aline Orr, Peter M. Frey, Robert P. Dolan, Victoria Vassileva, Aaron McVay (2012) A Literature Review of Gaming in Education Retrieved from http://researchnetwork.pearson.com/wpcontent/uploads/lit_ review_of_gaming_in_education.pdf. 